\title{
SAN JOSÉ, UNA CIUDAD EN PERPETUA TRANSFORMACIÓN. REFLEXIONES SOBRE EL ESPACIO
}

\section{SAN JOSE, A CITY IN PERPETUAL TRANSFORMATION. REFLECTIONS ON SPACE}

\author{
Adriana Sánchez Lovell * \\ Laura Paniagua Arguedas \\ Mónica Brenes Montoya
}

RESUMEN

\begin{abstract}
Este artículo discute las transformaciones históricas y las contradicciones presentes en las dinámicas, las relaciones, los significados y las creencias cotidianas sobre la ciudad de San José. Desde el espacio, como unidad analítica básica, se plantean cuestionamientos sobre los cambios en el ámbito social, relacional, productivo y laboral que se han presentado a lo largo de la historia de San José. Además, se discurre sobre las formas de apropiación y uso del espacio que se enmarcan en la segregación y discriminación crecientes.
\end{abstract}

PALABRAS CLAVE: SAN JOSÉ, CR * CIUDAD * ZONAS URBANAS * TRANSFORMACIONES SOCIALES * SOCIOLOGÍA URBANA

ABSTRACT

This article aims to introduce questions and proposals to approach the study of the transformations, contradictions and continuities present in the dynamics, relationships, meanings and everyday beliefs about San Jose city. We use space as our basic analytical unit, where we approach questions about changes in the social, relational, productive and labor sphere that arose in the last decades in the Costa Rican capital, and happen to gerate differentiated forms of appropriation and use of space that is increasingly characterized by segregation and discrimination.

KEYWORDS: SAN JOSE, CR * TOWN * URBAN AREAS * SOCIAL TRANSFORMATION $*$ URBAN SOCIOLOGY

Instituto de Investigaciones Sociales (IIS) de la Universidad de Costa Rica.

adrilovel@gmail.com

** Instituto de Investigaciones Sociales (IIS) de la Universidad de Costa Rica. lauparg@gmail.com

**** Instituto de Investigaciones Sociales (IIS) de la Universidad de Costa Rica. mobm17@gmail.com 


\section{INTRODUCCIÓN}

Una mañana de enero en el café La Españolita, ubicado al costado este del Teatro Popular Mélico Salazar, reconstruíamos imaginariamente la historia y el pulso de una ciudad, con la que iniciábamos nuestros encuentros y recorridos. La estructura de la cafetería que nos albergaba, nos hacía pensar en el proyecto de industrialización del país, pues por sus paredes de ladrillo, tubos y cuartos anexos, daba la impresión de haber funcionado anteriormente como una factoría de pequeña o mediana producción, cuyas instalaciones se transformaron al servicio de las y los pasantes que requieran consumir una bebida o comida.

La reflexión, así como, la discusión que involucró a uno de los trabajadores del Café, provenían de un interés por las transformaciones que ha sufrido el espacio de la ciudad de San José, en relación con los cambios en las actividades productivas que en las últimas décadas, ha variado de sus iniciativas de industrialización a una economía de servicios. Algunas de las industrias, especialmente de producción nacional para el mercado interno, ya habían hecho desaparecer gran parte de la producción basada en el sector primario, sobre cuyas ganancias reposaron las bases que edificaron los primeros cimientos que hoy se conservan de esa ciudad.

A partir de los recorridos por calles y reflexiones, el proyecto Vivencias callejeras y encuentros en la ciudad discute los conflictos, los límites en la ciudad, lo permitido, lo prohibido $y$ las transgresiones en el espacio físico $y$ el espacio simbólico, lo imaginario y lo administrativo en la ciudad, desde un enfoque etnográfico. Entre otras interrogantes, cuestiona las vivencias y los encuentros asociados a los procesos de construcción, uso y apropiación del espacio por parte de las y los habitantes de San José.

La ciudad es el terreno privilegiado de la confrontación política, las disputas económicas, las luchas por el poder, los problemas sociales, entre otros. La ciudad es el sitio de expresiones culturales diversas. Espacio donde se tejen añoranzas, sentidos y contrasentidos.

La ciudad de San José constituye el terreno donde se ha investigado durante los años
2011 y 2012, teniendo como participantes y protagonistas a las y los peatones. Estas personas han contribuido a cambiar nuestros puntos de partida $y$ a crear nuevas preguntas sobre las relaciones e intercambios en el espacio urbano, en específico, preguntarse sobre los conflictos en el espacio urbano que escenifican vendedores ambulantes, personas que viven en la calle, policías y colectivos juveniles.

Este artículo da cuenta de las transformaciones en las actividades económicas en el espacio. Este se encuentra dividido en tres secciones. La primera, realiza un recorrido histórico por la ciudad de San José y las huellas en el espacio que han dejado los cambios sociales, políticos y económicos, en el marco de las ciudades contemporáneas. Una segunda parte, explora la situación de los trabajadores $y$ trabajadoras que realizan ventas ambulantes en San José, como protagonistas de una de las principales luchas por el espacio urbano desde el siglo pasado, pero que se agudiza a inicios del siglo XxI. Finalmente, la última parte del artículo, aborda algunas de las transformaciones necesarias en la ciudad.

El artículo es el primero de una serie de publicaciones producidas en el Proyecto. Se ubica en un momento inicial de investigación, teniendo como objetivo abrir una discusión de puntos analíticos, basada en las primeras impresiones e interrogaciones causadas por los encuentros con voces, pieles, colores y texturas variadas en la ciudad, que es a la vez muchas ciudades.

\section{SAN JOSÉ: DEL GRANO DE ORO AL COMERCIO}

Los distritos Catedral y Merced son, de cierta forma, testigos de una problemática que afecta a todo el territorio nacional, por eso cabe situar el marco más amplio del proceso de restructuración económica en Costa Rica, en el contexto mundial y globalizado, el cual al modificar las actividades productivas en la capital como en la mayor parte del territorio, pasó a ser sinónimo de sentimientos de desarraigo para muchas personas.

El desarrollo de la ciudad de San José durante el siglo XIX y mitad del XX, estuvo íntimamente ligado a la llegada, el apogeo y el 
declive del café (Fumero, 2005; Molina, 1995 y Quesada, 1996, 2003 y 2007).

Algunos profesionales, desde el campo de la historia, han investigado estos orígenes y cambios. Actualmente se cuenta con textos especializados en historia de la ciudad, como el recién publicado por Florencia Quesada (2011) titulado: La modernización entre cafetales San José-Costa Rica 1890. Quesada examina los orígenes históricos de la segregación en la ciudad de San José y en su análisis evidencia las nuevas formas de distribución de las clases sociales en el espacio, en momentos en que el "ambiente de la élite" buscó diferenciarse por la ocupación de los espacios de ocio de los sectores populares.

Bastaría esa apreciación, para que a partir de los años comprendidos entre 1940 y 1950 cuando, de acuerdo con Jorge León (s.f.), la creciente urbanización de los gamonales y un marcado interés e impulso a la tecnología y a la ciencia, como base del desarrollo agropecuario, contribuyeron a cambiar el escenario económico y urbano del país, en momentos en que la economía se iba orientando hacia el sector secundario.

Este desarrollo de la agroindustria, se vincula por un lado, con la necesidad de subsanar las carencias derivadas de la reducción de la importación de ciertos artículos y por otro lado con la oportunidad — dirigida por misiones estadounidenses - de producir otros artículos, los cuales fueron demandados por la industria bélica.

Por parte del Estado, las lecciones económicas que dejaron la Gran Depresión y la II Guerra Mundial propiciaron que a partir de los 40, con mayor profundización en los 50 , se diera una intervención estatal en ampliación de servicios públicos de apoyo para el fomento de la producción agropecuaria, la capacitación tecnológica y científica para la producción, y mayor intervencionismo en el comercio internacional. También creció la cantidad de entidades, tales como cooperativas (León, s.f.).

De manera que, en las décadas del 50 al 70 del siglo pasado, el país se caracterizó por disminuir las brechas de desigualdad, pobreza y aumentar las posibilidades de movilidad humana. Esto se debió a la inversión estatal en infraestructura física y social a largo plazo, la permanencia del sector agroexportador, el impulso al sector industrial sustitutivo de importaciones en el marco del Mercado Común Centroamericano y la creciente participación del Estado en diferentes áreas. Juan Diego Trejos (2011) menciona que para este período, las políticas sociales fueron complementarias a las políticas económicas.

A inicios de los 80 , viene la siguiente crisis vinculada a la caída en los precios de exportaciones, el incremento en los precios de importaciones primordiales para la producción (como el petróleo) y al peso de la deuda externa en el marco del aumento en las tasas de interés del sistema financiero internacional. De acuerdo con Lizano (1992), en 1981 y 1982, la inflación alcanzó un $80 \%$ anual, el Producto Interno Bruto (PIB) cayó un 10\%, el desempleo abierto alcanzó al 9\% de la fuerza laboral y hubo una importante devaluación del colón respecto al dólar estadounidense, la cual estuvo acompañada de un aumento en el déficit fiscal.

El Programa Ajuste Estructural fue la respuesta que los organismos internacionales promovieron en América Latina para "paliar" la crisis. Este plan implicaba reducir el tamaño y la intervención Estatal, el fomento de exportaciones no tradicionales, la disminución o eliminación de tributos y barreras a las importaciones, $y$ el desgarre del proteccionismo estatal a pequeños y medianos productores.

En términos generales, la apertura y el neoliberalismo eliminaron las posibilidades de las amplias mayorías de insertarse en empleos de especialización intelectual, tecnológica, artesanal, agrícola y obrera de su preferencia. Este modelo ha incrementado las inequidades de acceso, uso y apropiación del espacio rural y urbano, tanto en el área central como en los sectores costeros del país.

Lo central y lo específico desde el neoliberalismo de acuerdo a sus impactos sobre el paisaje urbano, radica en que desde la crisis de los 80, el Estado se ha concentrado en el comercio internacional y la política macroeconómica, en lo que respecta a las finanzas y al comercio exterior, descuidando o "relegando los temas mesoeconómicos, sectoriales y regionales a un 
plano muy posterior" (PRUGAM, 2007). En la periferia, la masiva descampesinización fue paralela a promesas de reincorporación de las $y$ los trabajadores del campo al sector secundario y posteriormente terciario, que muchas veces no se llegaron a materializar, lo cual produjo una serie de consecuencias para estas personas y el país.

Los modelos de Sustitución de Importaciones y especialmente, el de Ajuste Estructural, intervinieron para bien y para mal en los índices de desigualdad y pobreza, y fluctuaron en las tasas de crecimiento económico, propiciando intensos y cambiantes movimientos migratorios entre el centro y las afueras, la ciudad y el campo, así como, migraciones transfronterizas que impactaron y generaron transformaciones en gran cantidad de comunidades, otrora ligadas a la producción agraria. Estos procesos de desplazamiento provocaron un reordenamiento - caótico- del espacio urbano, donde el derecho humano a la ciudad es uno de los grandes sacrificados. En palabras de Harvey:

La cuestión de qué tipo de ciudad queremos no puede estar divorciada de la que plantea qué tipo de lazos sociales, de relaciones con la naturaleza, de estilos de vida, de tecnologías y de valores estéticos deseamos. El derecho a la ciudad es mucho más que la libertad individual de acceder a los recursos urbanos: se trata del derecho a cambiarnos a nosotros mismos cambiando la ciudad. Es, además, un derecho común antes que individual, ya que esta transformación depende inevitablemente del ejercicio de un poder colectivo para remodelar los procesos de urbanización. La libertad de hacer $y$ rehacer nuestras ciudades $y$ a nosotros mismos es, como quiero demostrar, uno de nuestros derechos humanos más preciosos, pero también uno de los más descuidados (2009: 1).

A propósito, Neil Smith (s.f.) profundiza la manera en como, con el neoliberalismo, se transformaron profundamente el rol y el destino de las ciudades. Deudor de la obra de
Lefebvre, quien para 1970 vaticinaba que la urbanización sustituiría a la industrialización como eje histórico de la producción del espacio, Smith sostiene que el neoliberalismo de la mano con la globalización, hace de las ciudades urbanas crecientemente plataformas de la economía mundial, en sustitución de las que antes fueran reservas laborales de la economía nacional (Smith 2002, citado por Smith s.f.).

Ligado a ello, la emergencia del comercio en consorcio con la globalización, ejemplifica una dimensión problemática de la urbanización $y$ de lo urbano. La construcción de infraestructura $y$ de facilidades para esas zonas encara en sí misma, inversiones de billones de dólares de capital productivo. Más aún, la restructuración de ambientes urbanos, llámese residenciales, recreacionales o ambientales, juega un papel central en la economía mundial, tanto a nivel de las contrataciones para las firmas constructoras como en términos del turismo global. De la mano con ello, se encuentra la gentrificación de barrios empobrecidos, como la que sufren los otrora barrios obreros en la capital (Smith, s.f.).

Ahora bien, Smith sostiene que la sistemática crisis urbana en relación con el sistema económico neoliberal, puede puntualizarse en relación con la alta densidad de población en las urbes experimentada en la actualidad. Según las Naciones Unidas, el 50\% de la población mundial vive en ciudades, lo cual ha generado en las últimas dos o tres décadas, un crecimiento sin precedentes de edificaciones en la ciudad en Asia, Suramérica, Centroamérica y África. También se dan corrientes contrarias en el caso de potencias como China, la que, a consecuencia de la crisis más reciente, sufrió un desaceleramiento económico importante e hizo que veinte millones de trabajadores urbanos fueran devueltos de la ciudad a las villas de donde provenían, esto durante el 2009.

Otro factor que da cuenta del cambio producido con las políticas neoliberales, se vincula con el destino de los asentamientos informales y los sectores informales de la economía. Si bien, desde los setentas y ochentas, se sabía de la vinculación entre las economías formales e informales, la mayoría de las investigaciones han tendido a enfatizar en sus diferencias, lo 
cual no es extraño. El fin de las economías informales fue planteado por muchas burguesías formales del tercer mundo, como entonces se le denominaba. Sin embargo, la conjunción del neoliberalismo y la globalización, cambiaron el panorama. Por un lado, las lógicas del mercado transnacional permiten que muchos produzcan desde lo informal para su comercialización en grandes compañías formales. Por otro, el embate neoliberal y las políticas antiproteccionistas han debilitado las industrias nacionales y a los Estados, generando que contingentes inmensos de personas queden fuera de las posibilidades de acceder por la vía normativizada a los recursos de tierra, techo $y$ servicios, obligándolas a vivir en asentamientos informales (Smith, s.f.), pero también, haciéndoles preferir o depender de actividades informales de la economía frente a los bajos salarios que pagan muchas de esas empresas, asentadas en los países de "tercer mundo" con disfrute de preferencias taxativas y el privilegio de la explotación irracional de recursos sin pago de externalidades.

Si bien, muchos pequeños productores han luchado por "formalizar" sus empresas, la corrupción de una economía cada vez más privatizada ha conducido a una confusión mucho más mordaz respecto a las fronteras entre la economía formal e informal. Ni qué decir de las fronteras entre residenciales y la cantidad cada vez mayor de personas viviendo en asentamientos informales, excluidos del derecho a la tierra por un sistema que inherentemente no les brinda los recursos para adquirirla por los mecanismos "formales" a pesar de su esfuerzo, lo cual se ha rigidizado e intensificado con el régimen de seguridad actual (Smith, s.f.).

Los distritos centrales de San José, en los que se ha enfocado este estudio, son Merced y Catedral, los cuales han sufrido intensos procesos de despoblamiento en las últimas décadas debido a los procesos de gentrificación. Es decir, que del poblamiento de sectores populares se fueron transformando las zonas o barrios a espacios exclusivos de gran plusvalía que expulsaron a esos sectores. Además, dichos grupos han sido desplazados ante un fabuloso impulso al comercio y al sector servicios.
En esos distritos, las actividades económicas actuales, prácticamente se restringen a aquellas del sector terciario, mientras que únicamente concentran en su territorio $3,25 \%$ y $3,53 \%$ - respectivamente - de zonas verdes y recreativas (Municipalidad de San José, 2011). La escasez de este tipo de zonas afecta la estética, la salud y la sustentabilidad en la ciudad. Se ha procurado revertir el despoblamiento sufrido por los distritos centrales de San José, por ejemplo, mediante la construcción de torres de apartamentos; sin embargo, no son accesibles a las mayorías, lo que podría agravar los procesos de gentrificación y desigualdad en la ciudad. En este sentido, la Municipalidad de San José se encuentra realizando un estudio del uso de edificios e inmuebles para ver alternativas.

Otros graves aspectos por resolver radican en la alta densidad de tránsito de transportes automotores; los problemas de contaminación sónica, de desechos sólidos, de aguas, aire y la escasez de áreas verdes privadas y públicas. Sin embargo, las fortalezas de San José son la alta densidad de personas que le atraviesan y visitan día a día, muchas de las cuales se apropian de espacios como parques, plazas, monumentos, edificios históricos, museos, cines tradicionales (aunque han ido desapareciendo), teatros, hospitales, sodas, restaurantes, hoteles, bares y cantinas.

\section{SAN JOSÉ: ESPACIO PRODUCIDO, ESPACIO PRODUCTIVO}

La ciudad es un espacio de producción y es un espacio producido. Es una construcción, algunas veces más regulada que otras. En esta sección, se hará referencia a las dimensiones productivas de la ciudad, en relación con los tres nudos problemáticos de las consecuencias del neoliberalismo y la globalización sobre las ciudades. Atender las diferencias en las zonas de estudio - los distritos Catedral y Merced-, presenta una manera de profundizar en los mecanismos de inclusión y exclusión que promueven los distintos espacios, según las prácticas que se propician y los intereses envueltos alrededor de los mismos.

La producción del espacio no puede estudiarse desligada de las personas que lo habitan, 
ni de los conflictos y contradicciones inherentes a las dinámicas desiguales del mercado local y global. Como punto de partida, cabe señalar que en los últimos meses, en la capital costarricense, particularmente en el casco central, se han intensificado algunos conflictos presentes a lo largo de la historia (Acón, Ardón y Mora, 1993; Meoño y Muñoz, 1997), por ejemplo, entre vendedores ambulantes $y$ las autoridades municipales (Mata, 2009 y Estrada, 2009). Esta situación ha acrecentado el interés por conocer los vínculos y las relaciones entre estos actores en la ciudad, así como, ha reposicionado en la opinión pública el tema de las ventas en espacios públicos, el tránsito peatonal, las políticas municipales $y$ además, las tensiones y enfrentamientos caracterizados por importantes niveles de violencia.

Muchas veces, esto se debe a la presión por el espacio y los recursos de la ciudad, pues San José no solo concentra la mayor parte de la población, sino que además es una importante zona de paso dado que allí confluyen las estaciones de autobús de todas las provincias del país y muchas de las vías interprovinciales. A propósito, la concentración de vías de comunicación que tienen como núcleo San José, propicia una alta densidad de tránsito y el encuentro de muchas personas provenientes de diversas latitudes reunidas en el espacio por distintos intereses. Cabe preguntarse: ¿en qué medida la estructura posibilita la inclusión de unos grupos y la exclusión de otros en un espacio?, ¿cuáles actividades son permitidas y propiciadas por el espacio?

En parte, se puede decir que San José es espacio de inclusión que privilegia el paso rápido y el consumo. Pero a su vez, en la capital se reúnen cantidad de personas que ejercen actividades cotidianas de recreación y esparcimiento, sin que necesariamente medie la premura. Incluso, allí confluyen personas que en sus prácticas cotidianas, logran apropiarse de la ciudad a manera de intercambios, encuentros $y$ vivencias. Surge la interrogante respecto a qué significa para las distintas personas estar o visitar San José y a qué actividades se liga la visita a la ciudad, dándole especial énfasis a las diferencias entre las vivencias en San José como sitio de paso y aquellas en las que el casco central es un lugar para permanecer.

De manera que, un primer contingente importante de trabajadoras y trabajadores en la capital que se quisiera destacar como parte del proceso investigativo para profundizar en este artículo, dado el nivel de conflicto y represión que ha significado históricamente pero que se ha intensificado recientemente, lo constituye el colectivo conocido como vendedoras y vendedores ambulantes, algunos de los cuales pasan la mayor parte de sus días en las calles de la capital, sin horario, feriados ni garantías laborales. Este grupo ha pasado por algunas interesantes transformaciones a lo largo del tiempo. Por ejemplo, desde que se construyó el boulevard Avenida Central, estos dejaron de limitarse al espacio de las esquinas y los bordes de las calles, para pasar a erigir sus puestos en el pleno centro del boulevard, con mayor libertad en horarios nocturnos y ciertos días de la semana o fechas del mes, aspecto cuya explicación es parte de lo que se quiere explorar.

Este grupo heterogéneo de personas que parece aumentar día a día, es la expresión de las distintas transformaciones del trabajo (que ha visto reducidas las formas de estabilidad laboral, salarial y de garantía de derechos), así como, la reducción del Estado de bienestar, con la consecuente disminución de programas de atención en esa línea que van conformando las nuevas formas de pobreza (Wacquant, 2006).

Desde una óptica meramente infraestructural y no de las potencialidades de desarrollo que ofrece para los distintos grupos humanos, el director de la Policía Municipal sostiene que actualmente, San José está mejor que hace cinco o seis años, gracias a zonas peatonales, pasos transversales, además de indicar que se está mejorando la ciudad para que sea un lugar de destino más que de tránsito. En sus palabras: "La ciudad que todos merecemos y la cara del país cuando presentamos Costa Rica" (La Nación, $1^{\circ}$ de febrero de 2012).

También, manifiesta que el repoblamiento de San José se desplaza desde la zona oeste, teniendo como referente La Sabana, pero se espera que luego se haga extensiva a la zona de la capital que podemos llamar "más conflictiva", 
por el caos vial y por las ventas ambulantes. Por supuesto, aquí se contraponen los asentamientos formales, como las torres gestionadas por la Municipalidad, a las cuarterías, los hoteles y las casas de alquiler que prevalecen en los distritos centrales de la capital y que son habitados por sectores populares.

En el caso del comercio informal, un recurso de amparo interpuesto por un vecino ante la Sala Constitucional indicaba que las ventas ambulantes "obstruyen el tránsito de peatones, a la vez que afectan a adultos mayores y personas con discapacidad visual". A raíz de este recurso, se dio un fallo, en el cual la Sala Constitucional ordenó a la Municipalidad de San José y al Ministerio de Seguridad coordinar acciones para evitar las ventas en las calles ante la afectación a "los derechos fundamentales al ambiente, la salud y la seguridad de los pobladores y visitantes del lugar" (Corrales, 2012).

Según fue comunicado, la Municipalidad de San José se encuentra "dispuesta a eliminar ventas ilegales", lo cual no implica "que las autoridades se sentarán a dialogar con los vendedores para otorgarles zonas de tregua" (Municipalidad de San José, 2012).

Como se ha mencionado, las ventas ambulantes son un reflejo de la informalidad laboral de cada sociedad. La mayoría de quienes venden en las calles de la ciudad buscan sobrevivir, a partir de la venta de productos a bajo costo. La venta ambulante constituye en ocasiones un trabajo permanente, pero en muchos casos es una actividad a la cual se recurre ante la inestabilidad laboral, por ejemplo, en caso de ser despedido. Sin embargo, a esto habría que agregar que la economía depende tanto de lo que se califica de formal como de informal. Conviene diferenciar las calificaciones que al respecto, realiza el Estado de las representaciones de la ciudadanía.

A propósito, Kimuthia Macharia (2007) cuestiona la concepción dual de la economía en los sectores formal e informal que establecen el Estado y los centros de poder, calificando algunas actividades de ilegales e ilegítimas. El autor diferencia aquellas de las representaciones que al respecto se forma la ciudadanía, la cual realiza distinciones al interior de las actividades informales, dependiendo del esquema de valores morales, concibiendo positivamente aquellas que permiten la supervivencia de una mayoría pobre, pero también como importantes actividades del capital nacional $y$ fundamental fuente de trabajo especialmente para las mujeres.

Macharia (2007) subraya la importancia $y$ dependencia del sector informal de la economía, no solo como proveedor de empleos sino en términos de Producto Interno Bruto, a lo cual agrega que este sector también está atravesado por el modo político de proceder hacia los más empobrecidos: personas que carecen de condiciones adecuadas para trabajar $y$ de garantías o servicios del Estado. A pesar de ello, las divisiones entre la economía formal y la informal son mucho más etéreas de lo que parece, tan es así que incluso muchas veces un operador pertenece simultáneamente o realiza actividades paralelas en ambos grupos. Más aun, el tema está influenciado por políticas, formas de proceder económico y vínculos sociales heredados de la colonia para el caso de las sociedades pos coloniales.

En este ámbito, es importante retomar que deben superarse las perspectivas que reducen el sector informal a sobrevivencia de los más pobres, tradicional en los enfoques de los años 70, evidenciando la importancia de este sector para el desarrollo económico y social de los países. No obstante, cabe definir de qué se trata este sector o a quiénes estamos comprendiendo dentro de la condición de informalidad en este caso (el de la artesanía o las ventas al detalle en las calles).

Para ello se recurre nuevamente a Macharia (2007) quien sostiene, que si bien el sector informal es heterogéneo, existen características concretas que lo distinguen de las actividades formales de la economía: 1) se requieren menores cantidades de capital para invertir en los comienzos de la actividad económica; 2) existe un mayor énfasis en los recursos individuales más que depender de mecanismos institucionales; 3) existen vínculos y dependencia con la economía formal; 4) el financiamiento suele provenir de fuentes informales, generalmente de la propia familia implicada en los negocios; 5) la contabilidad formal usualmente, 
no se da; 6) las invenciones de los participantes en este sector tienden a carecer de registro de patentes $y$ de protección a la propiedad intelectual; 7) el ritmo de la producción es variable; 8) los trabajadores del sector informal generalmente, ganan menos y toman menor ventaja de los adelantos tecnológicos; 9) se trata de un sector más afectado por la incertidumbre; 10) las jornadas suelen ser extremas y no se respetan los feriados ni las fechas festivas y 11) las actividades generalmente se hacen escapando de los controles de la policía, temiendo su represión y esto determina la continuidad de las actividades que allí se desarrollan.

De igual manera, se trata de un sector generalmente, atravesado por la incertidumbre; además, las personas que laboran bajo ese régimen tienden a trabajar durante jornadas extremas durante las cuales no se respetan los feriados ni las fechas festivas; existen vínculos con la economía formal, por lo que la dualidad es un poco antojadiza y no solo eso, sino que existe dependencia hacia dicha forma económica. Sumado a lo anterior, los trabajadores del sector informal generalmente, ganan menos $y$ toman menor ventaja de los adelantos tecnológicos.

Estas características distinguen a los sectores más golpeados por la informalidad, pero también la informalidad involucra a personas poderosas, empresas y organizaciones que explotan a diferentes grupos, las cuales constituyen piezas fundamentales para la supervivencia del sistema capitalista y de las fronteras, así como, de la riqueza de las naciones; pero para estos sectores las leyes difícilmente se encuentran al pendiente. Como pasa por ejemplo, con las redes de narcotráfico, la trata de personas $y$ el mercado de las armas.

En todo caso, la informalidad es cambiante e históricamente definida y reprimida según las circunstancias. Esto se evidencia en Costa Rica, particularmente en San José, respecto a la persecución policíaca de las ventas callejeras. Cuando se inició el proyecto de investigación había un pulso entre las autoridades locales y el sector informal, pero muchas de las estrategias que se mencionan a continuación les permitían a estos realizar sus actividades económicas. Actualmente, su presencia es prácticamente nula en los principales boulevares de la ciudad, dado el nivel que ha alcanzado la represión de esta forma de vida. Actualmente, si la mercadería se les confisca, pueden perderla del todo o tienen que pagar una multa de 3000 colones para recuperarla, de acuerdo a una conversación informal con policías municipales. Sin embargo, la persecución policíaca no aplica para la totalidad de ellos y ellas, pues cabe decir que existen dos tipos de trabajadores: unos que laboran sin permiso de la Municipalidad y los otros que laboran en espacios autorizados por dicha instancia.

Por ejemplo, en la zona de La Coca Cola, una localidad en estudio, se podía ubicar hasta enero y febrero de 2011, a una cantidad importante de vendedores de mercadería tecnológica, tales como, discos, películas, relojes y estuches para celular; también está la venta tradicional como la de periódicos, una de las actividades comerciales callejeras de más largo alcance; además que existían fruteros, verduleros, confiteros y también había quienes vendían repostería y productos hechos con sus propias manos. Ahora su presencia es muy escasa. La siguiente imagen ilustra algunas de esas ventas, las cuales están prácticamente desaparecidas, producto de la represión.

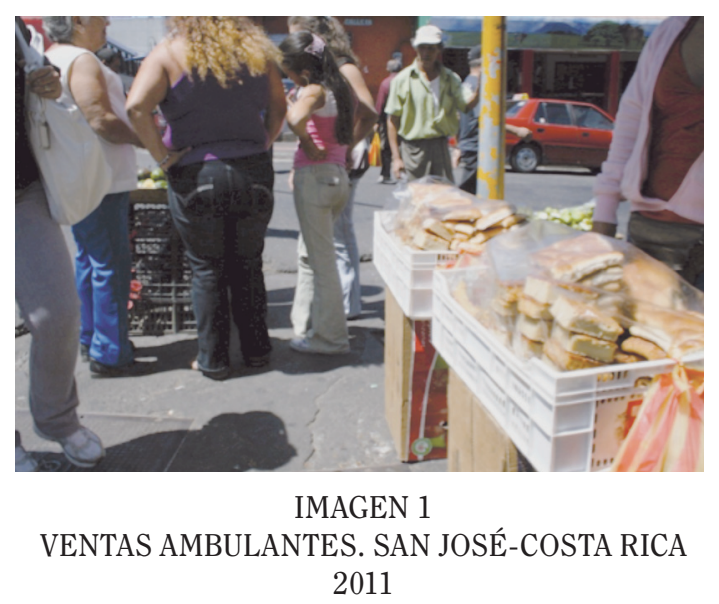

Un factor común en los discursos emitidos por los medios de comunicación a la mayoría de instituciones públicas y a la población en general, es la presencia de la criminalización de la población. Habitualmente, se les califica 
como "delincuentes", "migrantes", "ilegales" (aunque en realidad nadie es "ilegal", hay quienes carecen de documentos), "distribuidores de drogas", "vagabundos", personas que no desean trabajar, etc. En este sentido, se podría decir que la criminalización como factor determinante de los discursos sobre las y los vendedores ambulantes, es utilizada como un atenuante que justifica cualquier acción represiva contra esta población.

Si bien, el fenómeno de las ventas ambulantes o informales no es nuevo, sí se puede decir que ha sufrido transformaciones importantes en las últimas décadas, cuantitativa $y$ cualitativamente hablando, en sus dimensiones $y$ en los abordajes que se propician en su entorno. Desde la perspectiva de la Municipalidad, estas transformaciones son representadas como un aspecto negativo. Por ejemplo, en palabras del alcalde josefino: "debe procurarse una organización que permita superar algunas manifestaciones negativas, como basura, ventas ambulantes e indigencia. Con una organización fuerte y consistente podrían controlarse esas situaciones" (Herrera, 2009).

Esto conlleva a referirse a los cuerpos de choque $y$ aparatos de control que operan contra las y los vendedores ambulantes. Primero, han existido diversas iniciativas para reorganizar los espacios en que laboran los comerciantes informales. Algunas de ellas exitosas, como el Mercado de la Coca Cola; otras más bien infructuosas, ejemplo que brinda el Mercado de las Vacas. El triunfo o no de dichas iniciativas, en mucho depende de que dichos mercados logren compenetrarse con las rutas cotidianas de las $y$ los habitantes josefinos $y$ atraer a los consumidores, al mismo tiempo que convencer a los vendedores de reubicarse en dichos establecimientos, analizando las ventajas y las desventajas que esto puede acarrear.

Segundo, en los últimos años ha existido un pulso en la Municipalidad de San José para que la Fuerza Pública, órgano del Poder Ejecutivo de la seguridad nacional, colabore con la Policía Municipal, en la detección, desplazamiento y decomiso de mercadería perteneciente a las y los vendedores ambulantes "informales", vigilancia que se extrema en ciertos espacios físicos que constituyen puntos estratégicos para el comercio "formal" y declaradas rutas turísticas, tales como, la Avenida Central, así como en ciertas épocas del año, ya sea a principios, en fin de año e inicios del curso escolar.

Anteriormente, la Fuerza Pública no solía actuar directamente reprimiendo las ventas ambulantes, hasta que en diciembre de 2012, se anunció un trabajo conjunto y también, por cuanto, la Sala Constitucional votó a favor de la denuncia que planteó el ciudadano Rafael Ángel Paniagua en contra del Ministerio de Salud, el Ministerio de Seguridad y la Municipalidad de San José, "quien alegó que las ventas obstruyen el tránsito de peatones y afectan principalmente a adultos mayores $y$ personas con discapacidad visual" en el cual se ordena la actuación y la cooperación entre ambos órganos, pues según el fallo las ventas ambulantes lesionan "los derechos fundamentales al ambiente, la salud $y$ la seguridad de los pobladores $y$ visitantes del lugar" (Municipal.cr, 24 de enero de 2012).A lo anterior se refirió el Director de la Fuerza Pública, Juan José Andrade: "No hemos sido notificados del fallo, pero independientemente de lo dicho por la Sala, en diciembre se anunció un trabajo conjunto para combatir esta problemática y ya se está poniendo en práctica" (Prensa Libre, 23 de enero de 2012).

Ante este fallo, grupos de vendedores y vendedoras, así como, miembros de la Asociación Costarricense de Vendedores Ambulantes (ACOVA) emprendieron protestas, recurrieron a los(as) diputados(as) y a la Sala IV con manifestaciones, posicionando su derecho al trabajo. Las marchas no tuvieron mayores resultados, teniendo como consecuencia un recrudecimiento de la persecución policial y la expulsión de buena parte de ellas y ellos de la ciudad.

Tercero, la Municipalidad de San José firmó el primer día del mes de febrero del año 2012, un Convenio de Cooperación Técnica Interinstitucional entre el Ministerio de Trabajo y Seguridad Social y la Municipalidad de San José, basados en los siguientes Artículos:

"Art. 1) El Estado debe procurar que todos tengan ocupación honesta y útil, debidamente remunerada". "Art. 2) ... el 
Ministerio de Trabajo y Seguridad Social promueve la descentralización de los servicios de empleo, mediante la participación activa de los Gobiernos Locales" y "Art 3) El artículo 72 de la Constitución Política de la República refiere a que el Estado mantendrá, mientras no exista seguro de desocupación, un sistema técnico y permanente de protección a los desocupados involuntarios, y procurará la reintegración de los mismos al trabajo".

De manera que, con la firma de dicho acuerdo, se dirige a los desocupados involuntarios residentes en el Cantón hacia el Sistema Nacional de Intermediación, Orientación e Información de Empleo, del que participan el Ministerio de Trabajo y Seguridad Social, el Ministerio de Educación $y$ el Instituto Nacional de Aprendizaje. Pero, además de las dificultades para que el Sistema pueda resolver la faltante de empleo en el cantón, cabe decir que el convenio solo cubre a los residentes en el cantón central de San José, a pesar de que muchos de quienes se establecen allí para hacer labores informales e informales provienen de otros cantones, tales como Desamparados, Montes de Oca, Curridabat y de otras provincias, como Alajuela.

Lo anterior, evidencia las dificultades que subyacen en la organización de ciertos grupos en el espacio habitado por distintos órganos de control social, en este caso la Policía Municipal y la Fuerza Pública. La situación se complica más en espacios públicos regulados, donde además actúa la seguridad privada, como es el caso de la Plaza de la Cultura. En este espacio, la presencia de la seguridad privada se presenta, pues un cuadrante de ella es el techo del Museo de Oro, administrado por una fundación, a la cual debe solicitársele autorización para realizar cualquier actividad.

Una contradicción inminente es que, pese a las críticas de algunas personas, de los medios de comunicación, de los comerciantes "formales" y de políticos locales, así como, de las nuevas disposiciones que han restringido la presencia de los y las vendedoras, el espacio de la ciudad es compartido por ambulantes, policías y los(as) apurados(as) transeúntes, quienes pasan generalmente, mirando de reojo y algunas veces, adquiriendo las mercancías que ofrecen estos y estas mercaderes. En ocasiones, debido a la premura y ansiedad de las y los vendedores ante la presencia cercana de la Policía Municipal, las compradoras y los compradores les acompañan con la mercadería en la mano en el paso rápido hacia la calle.

A pesar de la persecución, muchas vendedoras $y$ vendedores se arriesgan a la acción policial $y$ han ideado estrategias para evadir a las autoridades. Hay quienes utilizan plásticos en los cuales adhieren sus productos para levantarlos rápidamente y movilizarse en caso de que haya presencia policial. Otros prefieren cargar la mercadería en bolsas que les permiten levantarla rápidamente del piso e irse. En cuanto a la mercancía, a la mayoría de ellos y ellas se les ve vendiendo ropa de temporada, tales como medias de escuela, juguetes y abrigos, generalmente a menor precio que el que se ofrece detrás de los escaparates de las tiendas "formales".

En parte por esa razón, esta población no es del agrado de las y los comerciantes formales de los alrededores de la Avenida Central, quienes los acusan de entorpecer el paso y envilecer la estética en el espacio circundante. De manera que ellas y ellos se configuran como "un elemento" a combatir por la política local, que anuncia la realización de operativos o su disposición a redoblar esfuerzos para hacerles desaparecer de su territorio, pues consideran que las ventas ambulantes en el espacio de la ciudad no son la solución para hacer frente al problema del desempleo (Costa Rica Hoy, 10 de julio de 2009).

Sin embargo, como se ha venido diciendo, la informalidad es una fuente de empleo particularmente importante desde el neoliberalismo, con la desprotección a la clase trabajadora, la absorción de industrias y de empresas nacionales en manos de las grandes empresas transnacionales, lo cual ha significado una severa contracción en el acceso a la propiedad y a la tierra en nuestros días. Muestra de su importancia para la supervivencia de la población es 
actualmente, que desde 1990 hasta el 2009 el número de personas empleadas en el sector informal de la economía se duplicó, dado que pasó a ser de más de 300000 personas a más de 600000 en dicho periodo, como lo demuestra el gráfico 1. Para darse una idea de lo que significan esas cifras vale decir que el resto de los empleados componen cerca de 1100000 personas ubicadas formalmente $y$ cerca de 200000 agricultores.

\section{GRÁFICO 1}

EMPLEO POR SECTORES: FORMAL, INFORMAL Y AGROPECUERIO

COSTA RICA, 1990-2010

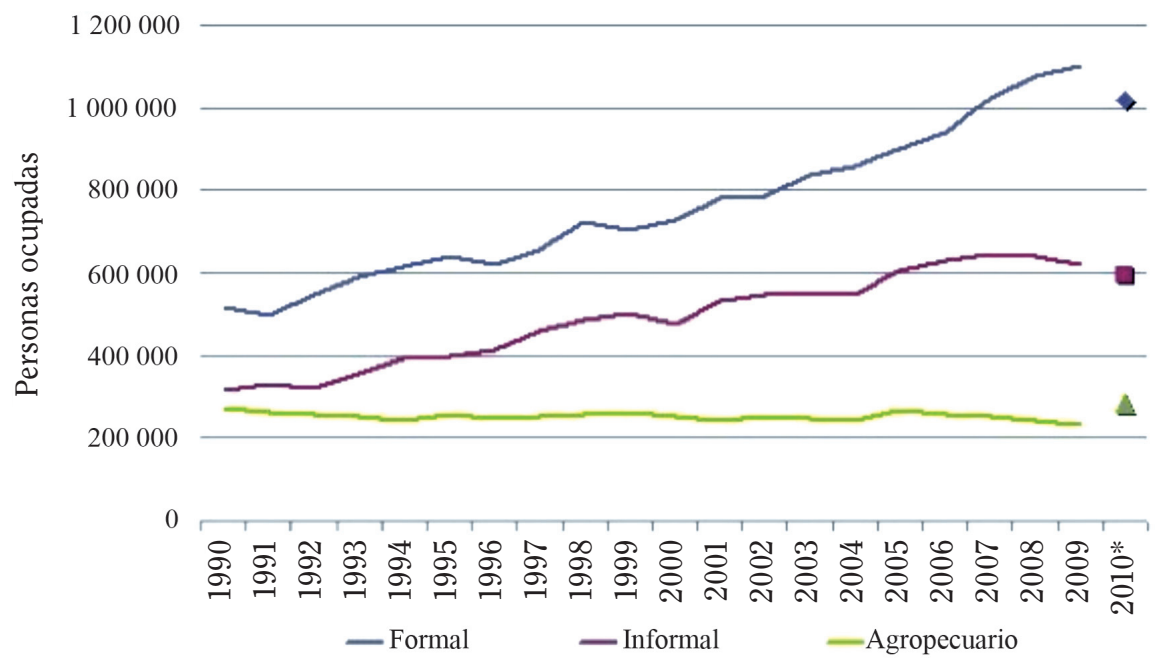

Nota: La estimación a partir de 2010, no es comparable con años previos, debido a cambios en la muestra y en el cuestionario, así como, al uso de las proyecciones de población en setiembre de 2008 para los factores de expansión.

Fuente: Estado de la Nación con base en las EHPM y la ENAHO del INEC, 2012.

De manera que no se debe dejar de lado el hecho de las condiciones estructurales que se imponen y que interaccionan con políticas que sofocan las posibilidades de supervivencia de muchas personas, además debe observarse y llamarse la atención respecto a las graves consecuencias que puede acarrear este grado de crueldad con que el sistema se impone contra muchos seres de carne $y$ hueso que tienen derecho a vivir.

Siguiendo con las políticas en el espacio de la ciudad, no deja de cobrar importancia, que cada vez hay menos habitantes de la calle en la Avenida Central. Esto no se debe de ninguna manera, a una mejora en la calidad de vida de quienes antes pedían dinero por estas calles, sino que esto es parte de un complejo proceso de segregación, probablemente ligado con la apuesta política hacia San José como la ciudad-patrimonio. La ciudad no es para todos $y$ todas, a pesar que se hable de lo contrario desde el Municipio. En actividades públicas, la policía municipal "saca" de los parques o boulevares a personas que viven en la calle. Estos hechos se han confirmado también, mediante entrevistas a oficiales, transeúntes y habitantes de la capital.

Esto se relaciona con las iniciativas encaminadas a hacer de San José, el centro de la ciudad, en un espacio cada vez más visitado, en un sitio turístico-comercial. Dichas iniciativas son en parte promovidas por las políticas de construcción de "espacios seguros", las cuales van orientadas a hacer de esta una ciudad que invite a sus habitantes, distinguidos por la población de clase media y por turistas extranjeros, a participar de actividades artísticas y culturales en los parques y los boulevares. 
TRANSFORMACIONES NECESARIAS EN LA CIUDAD

Si bien, San José es la ciudad capital, presenta en su historia una serie de situaciones que hacen pensar en las transformaciones dadas y las transformaciones necesarias.

Se ha propiciado, desde la Municipalidad de San José e instancias como el Ministerio de Cultura, brindar un reacomodo estético a la ciudad. En ese sentido, debe recordarse la prohibición en el uso de rotulación externa a los negocios desde el año 2005, a la vez que el Municipio ha colocado en la ciudad las estructuras denominadas 'mupis' (mobiliario urbano para información), sobre las cuales muchos habitantes han manifestado sus críticas debido a que por una parte, impiden la visibilidad y por otra, atentan contra la seguridad y las posibilidades de transitar por la acera, lo que provoca que las personas deban bajar a la calle y correr el riesgo de ser atropelladas. La mayoría son colocados en las paradas de autobús, impidiendo a las personas observar con anticipación la llegada del transporte que esperan. La obstaculización del paso y la mirada de esta manera, también hace pensar en la forma en la cual se busca eliminar la venta ambulante ante las dificultades de paso que ocasionan, pero otros inmobiliarios que generan amplia ganancia comercial, no son considerados como un impedimento para el paso. Esto nos lleva también a reflexionar sobre el lugar otorgado y legitimado que ha adquirido la publicidad en nuestras ciudades.

Un campo de transformación que debe apuntarse desde los esfuerzos municipales, estatales y privados corresponde el superar la visión de inversión en la ciudad únicamente en función del turismo. La oferta cultural, diurna $y$ nocturna, es necesaria en tanto constituye una forma para potenciar habitabilidad en la ciudad, pero también se hace necesaria la política municipal encaminada a revitalizar la ciudad, restringiendo por ejemplo, los lotes baldíos o abandonados. Un elemento tan simple como las limitadas ofertas de baños públicos (ubicadas fundamentalmente en los mercados), refleja la forma en que se potencia el uso de la ciudad únicamente para el paso o el consumo; el primero, al no incentivar quedarse en el espacio público y en lo segundo, al tener que consumir en lugares para poder tener acceso a los servicios sanitarios.

El repoblamiento de las zonas centrales y aledañas al centro de San José, no puede quedar en manos de las reglas del mercado y de la oferta inmobiliaria, la cual tiende a estar en función de generar ganancias a la inversión. Es urgente la búsqueda de alternativas de repoblamiento que potencien la atracción de poblaciones de muy diversas clases sociales y procedencias.

Como lo plantea Dania Chavarría (2011) en una investigación sobre repoblamiento inclusivo, ante la escasez de sitios para construir proyectos de vivienda de interés social en el centro de la ciudad a lo largo de la historia se ha estimulado, por un lado, a la construcción de apartamentos de bajo costo en edificios de tres o cuatro plantas $y$ por otro, los proyectos horizontales ubicados en terrenos en las áreas periféricas de la ciudad, lo cual es contradictorio con las últimas tendencias de sostenibilidad en la ciudad. Además, unido a esto se densifica donde no es apto, pues no hay servicios ni infraestructura. Entonces el modelo actual presenta la contradicción en la cual los costos de una vivienda digna superan los subsidios existentes (y eso se traduce en una baja calidad arquitectónica) y se margina a la población de bajos ingresos, generando sectores de la ciudad que son habitados casi exclusivamente por los sectores empobrecidos. La autora identifica que el papel del Estado en este modelo es de intervención en el financiamiento de proyectos, a través de los subsidios y la formalización de los casos; a la vez que son actores privados quienes asignan los subsidios y escogen los beneficiarios (aspecto político), quienes deciden la tipología de edificaciones y realizan la ejecución de los proyectos. Con ello, la población tiene un lugar pasivo en el proceso, al igual que las municipalidades que muchas veces se limitan exclusivamente a otorgar los permisos.

Como propuesta, Chavarría (2011) aboga por una alternativa de vivienda de alta densidad, explorando cómo puede ser viable la misma de manera subsidiada, debido al alto costo que implican las construcciones en altura. 
Con lo anterior, se potencia la inclusión social y la diversidad en la composición de las edificaciones.

En esta misma dirección, el transporte público y la movilidad en general deben optimizarse dentro de la ciudad de San José. El transporte público debe ser de los mejores servicios que brinda una ciudad. En términos de sostenibilidad, la fluidez en sus interconexiones es signo de una óptima articulación de sus componentes. El ingreso y salida de todo vehículo debe optimizarse, así como, debe potenciarse el uso mínimo del transporte privado. Para ello, se requiere un esfuerzo en donde sea prioritario el interés colectivo sobre el individual; con esto se apunta tanto al uso del vehículo a nivel privado como a los intereses de los empresarios del transporte. Las condiciones de transporte no mejorarán en el centro de San José si no se comienza por articular las rutas, según los puntos de destino, evitando que decenas de autobuses repitan las mismas rutas. Es decir, del centro deberían salir autobuses que conecten con los cantones principales del Gran Área Metropolitana (GAM) $y$ de allí, por medio de otro trasporte continuar las rutas hacia destinos más acotados. Se trata de liberar el espacio de pasos repetidos y establecer los necesarios, según el uso y la necesidad de la población que se dirige hacia esos destinos.

Un tema de atención urgente corresponde al manejo de desechos sólidos. A pesar de los discursos de protección ambiental y la llamada "moda verde", aún no se consolidan esfuerzos educativos y cotidianos para que la ciudad haga un manejo adecuado de los desechos. La tensión entre la sociedad de consumo y la preocupación ante los irreversibles cambios ambientales, producto de la acción humana sobre el planeta no permiten la toma de las decisiones políticas más urgentes, sino que parecen sumergirnos en un inmovilismo. Ciudades tan pequeñas como San José deberían posicionarse como modelo para el resto de ciudades del GAM, potenciando experiencias de mejoramiento urbano esenciales como la atención a los desechos, superando la acción tradicional de trasladar el problema a otros habitantes de la ciudad, que son generalmente las comunidades que enfrentan exclusión social, como el caso de La Carpio, donde fue colocado el depósito de basura más grande del Área Metropolitana.

\section{ALGUNAS CONSIDERACIONES FINALES}

La estética de la ciudad-patrimonio o el espacio institucional marcado por el nivel global o estatal, en palabras de Lefebvre, trata de ser impuesta desde el poder, como la ciudad estética y éticamente deseable, a manera de monumento. Esta visión es preformada por tecnócratas en urbanismo y alimentada por ideologías y estrategias del poder político. Las reacciones a esto son disímiles por parte de las y los habitantes de la ciudad, $y$ dependen no solo de consideraciones estéticas, sino también de sus necesidades e intereses. Por un lado, algunas personas se sienten posiblemente más invitadas a participar de un San José "más bonito"; por otro lado, muchas son efectivamente "desparticipadas' de este, al ser forzadas a salir de los escenarios urbanos que simbolizan estatus social y económico.

El impacto de las políticas neoliberales sobre las configuraciones en la ciudad es evidente. Por una parte, el gobierno local ha invertido millones de colones en recrear la infraestructura y crear espacios de esparcimiento al aire libre, así como, mejorar los ya existentes; sin embargo, ha quedado en deuda con el verdor $y$ la salud ambiental. Por otra parte, dichas políticas tienen un trasfondo segregativo: vendedores $y$ vendedoras ambulantes $y$ personas que viven en la calle están sujetos a la criminalización y se les subyugan las condiciones para apropiarse de dichos espacios de la ciudad. A menudo, se culpabiliza a las y los migrantes provenientes de otros países $y / 0$ a las $y$ los vendedores ambulantes de las causas de las actividades informales. Mientras tanto, las presiones sobre el espacio para la movilización, la habitación y el desarrollo de actividades productivas son resueltas en la práctica mediante estrategias de resistencia y supervivencia por parte de diversos colectivos. Desde el ámbito político, se habla de una política integrativa y educativa de la que sobresale; sin embargo, en sus manifestaciones, la cara represiva. 
Finalmente, cabe decir que nuestra propuesta respecto a lo posible, a lo utópico, radica en promover un espacio de gestión para las personas, para aquello que los y las habitantes desean $y$ anhelan de la ciudad, reivindicando el derecho a la calle como el sitio más importante para el encuentro, donde no necesariamente medie lo comercial y lo privado. La gestión tecnócrata de los espacios a menudo excluye $y$ olvida que cada habitante de la ciudad también está haciendo política, según los usos y la apropiación que realice sobre el espacio. Distintas formas de organización y diversas manifestaciones de protesta, son solo las caras más visibles de una serie de actividades y luchas por el espacio $y$ el derecho a la ciudad que se ejercen diariamente en la vida urbana. El pulso parece ganarlo los comercios formales y las fuerzas políticas tradicionales, pero las mayorías están en las calles, tratando de solventar sus necesidades básicas. Al respecto, se ha identificado una importante idealización por el San José de antaño. Nos preguntamos si acaso dicha idealización corresponde con la fragilizada concepción de país que sostiene la mayoría de sus habitantes o más bien, constituye una posibilidad de pensar en una ciudad distinta a la existente, de reflexionar sobre transformaciones con más color a gente, olor, humor y miradas desde quienes la habitan.

\section{REFERENCIAS}

Acón, Jeannette; Ardón, Evelyn y Mora, María. "Los medios de difusión ante los hechos inéditos de los desórdenes civiles provocados por los vendedores ambulantes en la Avenida Segunda. Julio de 1991". [Tesis presentada para optar por el grado de Licenciatura en Periodismo]. Ciudad Universitaria Rodrigo Facio, Universidad de Costa Rica, 1993.

Araya, Johnny. "San José: una ciudad para todos”. Programa de gobierno 20032007. Municipalidad de San José. (s.f.).

Chavarría, Dania. Repoblamiento inclusivo, vivienda de alta densidad y regeneración urbana para el distrito central del cantón de Goicoechea, San José.
[Trabajo presentado para optar por el grado de Magíster en Diseño Urbano]. Universidad de Costa Rica, 2011.

Corrales, Gloriana. "Sala IV exige quitar ventas ambulantes". Al Día. 24 de enero de 2012. En: <http://www.aldia.cr/ad_ee/2012/ enero/24/nacionales3047713.html>

Fumero, Patricia. Héroes al gusto y libros de moda. Sociedad y cambio cultural en Costa Rica (1750-1900). En: Molina, Iván y Palmer, Steven. San José: Editorial UNED, 2005.

Grosso, José Luis. "Cuerpo y modernidades europeas. Una lectura desde los márgenes". Boletín de Antropología 19 (36). 2005: 232-254.

Harvey, David. "El derecho a la ciudad". Carajillo de la ciudad 1. Universitat Oberta de Catalunya. 14 de abril de 2009. En: <http://cafedelasciudades.com.ar/>

Herrera, Luis Miguel. "Convertirán Avenida Central en gran centro comercial”. $L a$ Prensa Libre. 21 de setiembre de 2009. En: <http://www.prensalibre.cr/>

La Nación. "Chat con Marcelo Solano, Jefe de la Policía Municipal". 1ero. de febrero de 2012.

Lefebvre, Henry. La Revolución Urbana. $2^{\text {a }}$ edición. Madrid: Alianza Editorial, 1976.

León, Jorge. La economía rural en el sXX. Parte 2: 1940 a 2000. Universidad de Costa Rica. Instituto de Investigaciones en Ciencias Económicas. (s.f.). En <http:// www.iice.ucr.ac.cr>

Lizano, Eduardo y Monge, Ricardo. Apertura económica e industrialización en Costa Rica. Academia de Centro América y Friedrich Ebert Stiftung, 1997.

Macharia, Kimuthia. "Tensions created by the formal and informal use of urban space: the case of Nairobi, Kenya". Journal of Third World Studies 24 (2). Fall, 2007: 145-162.

Mata, Alonso. "Policías y vendedores ambulantes se enfrentan con piedras y gases". La Nación. 3 de diciembre de 2009. En: <http://www.nacion.com/ln ee/2009/diciembre/03/pais2181933.html>

Meoño, Carmen y Muñoz, Vernor. De la ciudad y el chinamo: una historia de 
comerciantes de la calle. Defensoría de los Habitantes: San José, Costa Rica, 1997.

Ministerio de Trabajo y Seguridad Social y Municipalidad de San José. Convenio de Cooperación Técnica Interinstitucional entre el Ministerio de Trabajo y Seguridad Social y la Municipalidad de San José. 1ero. de febrero de 2012. En: <http://www.msj.go.cr/transparencia/ convenios/nacionales/con_89.pdf>

Molina, Iván. El que quiera divertirse. Libros y sociedad en Costa Rica (1750-1914). San José, Costa Rica: Editorial de la Universidad de Costa Rica y Editorial de la Universidad Nacional, 1995.

Municipalidad de San José. "Noticias municipales". Municipalidad josefina dispuesta a eliminar ventas ilegales. 2012. En: <http:// www.msj.go.cr/noticias/detalle_noticia. asp? encabe $z a=$ Municipalidad $\% 20$ Josefina $\% 20$ dispuest a $\% 20$ a $\% 20$ eliminar\%20ventas\%20ilegales>

Municipalidad de San José. División Territorial del Cantón. 2011. En: < http://www. msj.go.cr/gob_ciudad/distritos/catedral. html>

Noguera González, Jarmon. "Sala IV ordena desalojar a vendedores de las calles, La Prensa Libre". La Prensa Libre. 23 de enero de 2012. En: <http://www. prensalibre.cr/pl/nacional/57192-sala-ivordena-desalojar-a-vendedores-de-lascalles-.html>

Noticias Kolbi. Vendedores ambulantes protestan en San José. 08 de febrero de 2012. En: <http://noticias.kolbi.msn. com/vendedores-ambulantes-protestanen-san-jos\%C3\%A9>

Planificación Regional y Urbana de la Gran Área Metropolitana del Valle Central de Costa Rica (PRUGAM). Informe final. Estudio del marco institucional legal para el Plan GAM. Centro de Investigación y Capacitación de Administración Pública de la Universidad de Costa Rica, 2007.

Quesada, Florencia. "Los del Barrio Amón. Marco habitacional, familiar $y$ arquitectónico del primer barrio residencial de la burguesía josefina (1900-1930)". Mesoamérica 31. Junio, 1996: 213-241.

Quesada, Florencia. "El ambiente de la élite'. Modernidad, segregación urbana y transformación arquitectónica: San José, Costa Rica, 1890-1935”. Revista Electrónica de Geografía y Ciencias Sociales 146 (027). Universidad de Barcelona, 2003. En: <http://www.ub.es/ geocrit/sn/sn-146\%28027\%29.htm>

Quesada, Florencia. "La modernización entre cafetales. San José, Costa Rica, 1880-1930". [Tesis doctoral]. Facultad de Humanidades de la Universidad de Helsinki, Instituto Reenvía, 2007.

Quesada, Florencia. La modernización entre cafetales. San José, Costa Rica, 1880 1930. San José, Costa Rica: Editorial Universidad de Costa Rica, 2011.

Redacción. "Anuncian erradicación de ventas ambulantes en San José". Costa Rica Hoy. 10 de julio de 2009. En: <http:// crhoy.info/nacionales/anuncianerradicacion-de-ventas-ambulantes-ensan-jose/19165/>

Smith, Neil. Cities after neoliberalism? (s.f). En: $<$ http://www.neil-smith.net/>

Trejos, Juan Diego. "Pobreza, desigualdad y oportunidades: una visión de largo plazo. Proyecto preliminar para discusión”. Documentos de Trabajo. Instituto de Investigaciones en Ciencias Económicas de la Universidad de Costa Rica, 2011.

Villegas, Jairo. "Sala IV exige reubicar dos mupis por obstruir paso". La Nación. 23 de junio de 2010. En: <http://www. $\mathrm{nacion}$.com/2010-06-23/E1Pa is/ NotasSecundarias/EIPais2419423.aspx>

Wacquant, Loic. Castigar a los parias urbanos. Universidad de California, 2006. En: <http://sociology.berkeley. edu/faculty/wacquant/wacquant_pdf/ CASTIGARPARIASURBANOS.pdf>

Fecha de ingreso: 26/08/2011 Fechas de aprobación: 27/04/2012 
